\title{
Comparison of internal process control viruses for detection of food and waterborne viruses
}

\author{
María Dolores Blanco Fernández ${ }^{1,2}$ Melina Elizabeth Barrios ${ }^{1,3}$. \\ Robertina Viviana Cammarata $^{1,2}$ - Carolina Torres ${ }^{1,2}$ - Oscar Alberto Taboga ${ }^{2,4}$. \\ Viviana Andrea Mbayed ${ }^{1,2}$
}

Received: 8 December 2016 / Revised: 8 March 2017 / Accepted: 12 March 2017

(C) Springer-Verlag Berlin Heidelberg 2017

\begin{abstract}
Enteric viruses are pathogens associated with foodand waterborne outbreaks. The recovery of viruses from food or water samples is affected by the procedures applied to detect and concentrate them. The incorporation of an internal process control virus to the analyses allows monitoring the performance of the methodology. The aim of this study was to produce a recombinant adenovirus ( $\mathrm{rAdV}$ ) and apply it together with bacteriophage PP7 as process controls. The rAdV carries a DNA construction in its genome to differentiate it from wild-type adenovirus by qPCR. The stability of both control viruses was evaluated at different $\mathrm{pH}$ conditions. The rAdV was stable at $\mathrm{pH} \mathrm{3,} \mathrm{7,} \mathrm{and} 10$ for $18 \mathrm{~h}$. PP7 infectious particles were stable at $\mathrm{pH} 7$ and showed a $2.14 \log$ reduction at $\mathrm{pH} 10$ and total decay at $\mathrm{pH} 3$ after $18 \mathrm{~h}$. Three virus concentration methods were evaluated: hollow-fiber tap water ultrafiltration, wastewater ultracentrifugation, and elution-PEG precipitation from lettuce. Total and infectious
\end{abstract}

Electronic supplementary material The online version of this article (doi:10.1007/s00253-017-8244-2) contains supplementary material, which is available to authorized users.

María Dolores Blanco Fernández dblanco@ffyb.uba.ar

1 Cátedra de Virología, Facultad de Farmacia y Bioquímica, Universidad de Buenos Aires, Junín 956, 1113 Buenos Aires, Argentina

2 Consejo Nacional de Investigaciones Científicas y Técnicas (CONICET), Godoy Cruz 2290, 1425 Buenos Aires, Argentina

3 Ministerio de Ciencia y Tecnología, Agencia Nacional de Promoción Científica y Tecnológica, Godoy Cruz 2370, 1425 Buenos Aires, Argentina

4 Instituto de Biotecnología, INTA, Nicolás Repetto y de los Reseros s/n, 1686 Hurlingham, Buenos Aires, Argentina viruses were quantified and their recoveries were calculated. Virus recovery for rAdV and PP7 by ultrafiltration showed a wide range (2.10-84.42 and $13.54-84.62 \%$, respectively), whereas that by ultracentrifugation was $5.05-13.71$ and $6.98-13.27 \%$, respectively. The performance of ultracentrifugation to concentrate norovirus and enteroviruses present in sewage was not significantly different to the recovery of control viruses. For detection of viruses from lettuce, genomic copies of PP7 were significantly more highly recovered than adenovirus (14.74-18.82 and 0.00-3.44\%, respectively). The recovery of infectious virus particles was significantly affected during sewage ultracentrifugation and concentration from lettuce. The simultaneous use of virus controls with dissimilar characteristics and behaviors might resemble different enteric viruses.

Keywords Internal process control virus $\cdot$ Hollow fiber ultrafiltration · Ultracentrifugation · Lettuce $\cdot$ Sewage $\cdot$ Virus recovery

\section{Introduction}

Viruses are widely distributed in the environment, and due to fecal pollution, pathogenic human viruses are present in aquatic environments and crop fields. Enteric viruses have been increasingly recognized as pathogens associated with food- and waterborne outbreaks (Eurosurveillance Editorial Team 2014; Beer et al. 2015; Verhoef et al. 2015). Therefore, quantitative analysis of viruses in food, water, and environmental samples is required to address public health and environmental contamination, to evaluate disinfection processes, and to carry out routine quality monitoring (Charles et al. 2009; Summa et al. 2012; Matsushita et al. 2013; Barardi et al. 2014; Hata et al. 2014). 
The procedures involved in these kinds of studies affect virus recovery from the original matrixes (Bosch et al. 2008; Julian and Schwab 2012). The complexity of the analyses increases because virus recovery varies for each procedure and target virus (Victoria et al. 2009; Summa et al. 2012; Martin-Latil et al. 2014). Spiking samples with a control virus is necessary to monitor the viral concentration and detection methods and thus be able to expose possible failures. This control virus may act as a surrogate for the target virus and should be as related as possible to it in morphology and physicochemical properties (Lees 2010). The internal process control (IPC) virus should be easily quantified by both infectivity measurement and nucleic acid assays. Although pathogenic viruses like polioviruses, adenoviruses, and noroviruses have been used as spiked viruses in mock samples for development of methodologies (Victoria et al. 2009; Summa et al. 2012), they cannot be used as internal controls when these same viruses are the target of the detection in real samples. Then, viruses such as mengovirus or murine norovirus have been used as surrogates for hepatitis A virus and human norovirus, respectively (Costafreda et al. 2006; Coudray et al. 2013). Bacteriophages, like PP7 and MS2, have been used as IPC viruses in a variety of studies (Rajal et al. 2007; Bae and Schwab 2008; Poma et al. 2013). The advantages of using bacteriophages are their safety and simplicity of stock production, although these viruses differ in their physicochemical properties from human viral pathogens.

Recombinant human adenoviruses (rAdVs) can be used as IPC viruses. rAdVs are nonreplicative viruses because they lack the early gene E1, a genomic region involved in viral gene transcription and essential for its replication. rAdVs can only be grown in the 293A cell line, which possesses the E1 region integrated in its genome (He et al. 1998). One study has described the use of a recombinant adenovirus expressing green fluorescent protein to assay UV disinfection of drinking and sea water (Barardi et al. 2014). The incorporation of tagged DNA constructions into the genome of the rAdV could allow its differentiation from the wild-type adenovirus $(\mathrm{AdV})$. The aim of this study was to produce a nonreplicative recombinant adenovirus (rAdV-IPC) and apply it together with the bacteriophage PP7 as IPC viruses in procedures to detect viruses from food and environmental samples.

\section{Materials and methods}

\section{Design and production of primer sharing control DNA}

A construction (named IPC) that included a series of primer sharing control sequences (PSCs) of DNA from seven human enteric viruses was synthesized as gBlocks ${ }^{\mathrm{TM}}$ Gene Fragments (IDT, IA, USA) (Fig. 1). PSCs are short sequences of DNA $(100-150 \mathrm{nt})$ with the same quantitative real-time PCR
(qPCR)-targeted sequence as the viral genome, except for the TaqMan probe recognition sequence (Hata et al. 2011). The probe recognition sequences had the same nucleotide composition as the viral sequence and were randomly generated by an online software tool (https://www.genscript.com/ ssl-bin/app/scramble). The seven selected viruses are either responsible for food- or waterborne diseases or proposed as viral indicators of contamination. The qPCRs for their detections are based on previously published methodologies for AdV (Jothikumar et al. 2005a), JC polyomavirus (Pal et al. 2006), enterovirus (Monpoeho et al. 2001), hepatitis A virus (Jothikumar et al. 2005b), norovirus (Jothikumar et al. 2005c), hepatitis E virus (Jothikumar et al. 2006), and rotavirus (Zeng et al. 2008) (Supplementary material, Table S1).

\section{Generation of recombinant adenovirus}

Nonreplicative recombinant adenovirus containing the IPC construction (rAdV-IPC) was produced using RAPAd ${ }^{\circledR}$ Universal Adenoviral Expression System according to the supplier's instructions (Cell Biolabs, Inc., San Diego, CA, USA). Briefly, IPC was cloned in the shuttle vector pacAd5 $\mathrm{K}-\mathrm{NpA}$ in the EcoRI restriction site. The shuttle pacAd5 K$\mathrm{NpA}$ vector containing IPC and the pacAd5 9.2-100 backbone vector were linearized, purified, and used to co-transfect 293A cells with X-tremeGENE 9 (Roche Life Science, Mannheim, Germany). Adenovirus-containing cells were harvested and stored at $-80^{\circ} \mathrm{C}$ as crude viral lysate.

\section{Virus and cell lines}

rAdV-IPC was propagated in 293A cells (Invitrogen, Life Technologies, Carlsbad, CA, USA), which possess the E1 region of $\mathrm{AdV}$ integrated in its genome to allow its replication. Replication-competent adenoviruses were evaluated in A549 cells (ATCC ${ }^{\circledR}$ CRM-CCL-185 ${ }^{\mathrm{TM}}$ ). Cells were cultured in high-glucose Dulbecco's modified Eagle's medium (DMEM) or E-MEM (Life Technologies, Carlsbad, CA, USA), respectively, and supplemented with $10 \%$ fetal bovine serum (FBS) and antibiotics at $37{ }^{\circ} \mathrm{C}$ under a $5 \% \mathrm{CO}_{2}$ atmosphere. Bacteriophage PP7 (ATCC 15692-B2) was grown in an overnight culture of the host Pseudomonas aeruginosa (ATCC 15692) in nutritive broth at $37^{\circ} \mathrm{C}$. Viruses were stored at $-80{ }^{\circ} \mathrm{C}$ until use.

\section{Evaluation of the generation of replication-competent adenoviruses}

To verify the absence of replication-competent adenovirus particles, four blind passages of rAdV-IPC were performed in A549 cells. The inoculum was removed and cells and supernatant were harvested after 1 week at $37{ }^{\circ} \mathrm{C}$. The cythopathic effect (CPE) was monitored microscopically and 


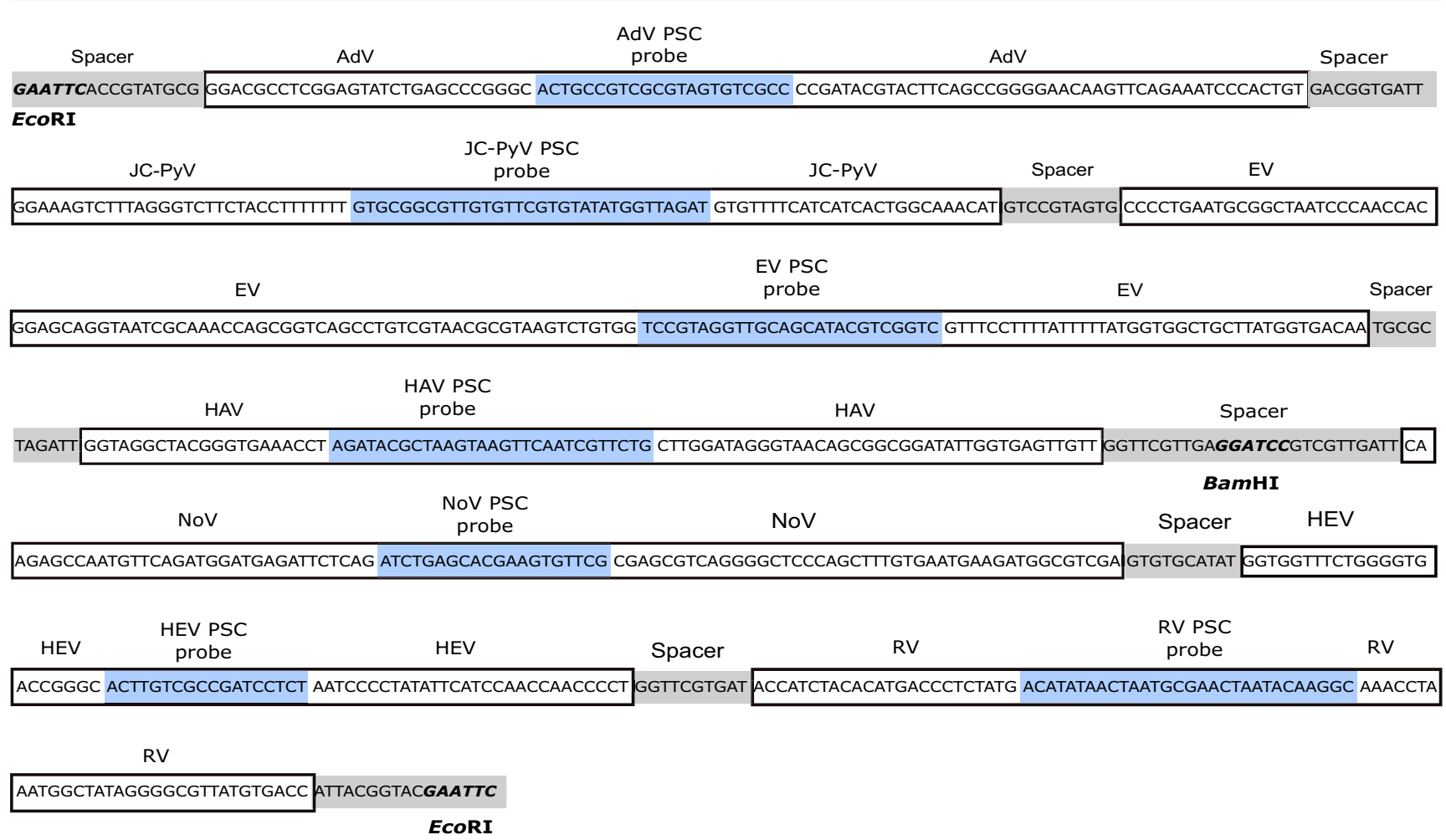

Fig. 1 Scheme of the construction of the internal process control (IPC) virus included in the rAdV-IPC genome

harvests were evaluated in a tissue culture infectious dose 50 (TCID50) assay.

\section{Infectious virus quantification}

Samples for AdV quantification by plaque assay were pretreated by performing a chloroform extraction (1:1) for $15 \mathrm{~min}$ at ambient temperature, and penicillin, streptomycin, and amphotericin B were added to the aqueous phase.

The plaque assay was performed as described previously for huAdV with modifications (Cromeans et al. 2008). Briefly, $1.4 \times 10^{5} 293 \mathrm{~A}$ cells per well were incubated in a 24-well plate for $24 \mathrm{~h}$ at $37{ }^{\circ} \mathrm{C}$ under a $5 \% \mathrm{CO}_{2}$ atmosphere. When $60 \%$ confluent monolayers were achieved, the growth medium was discarded, $150 \mu \mathrm{L}$ of decimal dilutions of sample were added to the cell monolayers in triplicate, and the cells were incubated for $120 \mathrm{~min}$ at $37{ }^{\circ} \mathrm{C}$ under $5 \% \mathrm{CO}_{2}$ atmosphere. After this period, the inoculum was removed and cell monolayers were overlaid with $2.0 \mathrm{~mL}$ of $0.8 \%$ methyl cellulose (4000 cp) in high-glucose DMEM containing 2\% FBS, $0.05 \mathrm{M} \mathrm{NaHCO}_{3}, 0.025 \mathrm{M}$ HEPES, and antibiotics and incubated at $37{ }^{\circ} \mathrm{C}$ for 15 days. After this period, cells were fixed with formaldehyde and stained with $20 \%$ Gram's crystal violet. Then, the stain was removed and plaques were counted macroscopically.

The infectious bacteriophage PP7 was quantified with a double-layer plaque assay as described before (Clokie and Kropinski 2001). Briefly, $75 \mu \mathrm{L}$ of a 16-h culture of
P. aeruginosa and $400 \mu \mathrm{L}$ of decimal dilutions of sample were mixed with $5 \mathrm{~mL}$ of semisolid nutritive agar ( $0.5 \%$ agar) and poured over nutritive broth agar plaques. Plaques were counted macroscopically after incubation overnight at $37^{\circ} \mathrm{C}$.

Results were expressed as plaque-forming units per milliliter $(\mathrm{PFU} / \mathrm{mL})$.

\section{pH stability of rAdV-IPC and PP7}

Sterile phosphate buffered saline (PBS) was adjusted to $\mathrm{pH} 3$, 7 , and 10 , using $1 \mathrm{M} \mathrm{HCl}$ or $1 \mathrm{M} \mathrm{NaOH}$. One volume of rAdV-IPC or PP7 viral stocks was mixed with 9 volumes of PBS with the aforementioned $\mathrm{pH}$ values. Each $\mathrm{pH}$ condition was assayed in triplicate. Suspensions were incubated at room temperature $\left(25^{\circ} \mathrm{C}\right)$ for $0,1,4$, and $18 \mathrm{~h}$, and then serial dilutions were immediately prepared in culture medium to neutralize the $\mathrm{pH}$. Diluted virus suspensions were used to determine titers of rAdV-IPC and PP7 by PFU per milliliter. Log reduction curves were built by representing Log $\left(\mathrm{PFU}_{t=x} / \mathrm{PFU}_{t=0}\right)$ versus time.

\section{Virus quantification by quantitative real-time PCR}

Virus genomic DNA and RNA were extracted from $200 \mu \mathrm{L}$ of viral concentrate using the High Pure Viral Nucleic Acid Kit (ROCHE Life Science), according to the manufacturer's instructions. Retrotranscription of virus RNA was performed using random primers as described before (Poma et al. 2013). 
PP7, norovirus, and enteroviruses were detected and quantified using previously described real-time qPCR protocols (Loisy et al. 2005; Rajal et al. 2007; Kilpatrick et al. 2009). rAdV-IPC was also detected and quantified using a previously described qPCR protocol (Jothikumar et al. 2005a) but replacing the original probe for the PSC-probe designed in this study (Table 1). Standard curves were generated using 10 to $10^{7}$ genomic copies (gc) from cloned amplification products for absolute quantification.

The real-time TaqMan PCR assays were performed using the FastStart Universal Probe Master (ROX) mix (ROCHE Life Science) in an Applied Biosystems ${ }^{\circledR} 7500$ Real-Time PCR system. All amplification reactions were carried out in duplicate.

\section{Virus concentration from water and food samples}

Virus recovery was attempted in three kinds of samples: tap water samples, wastewater effluents, and lettuce. Viruses were concentrated by ultrafiltration, ultracentrifugation, and elution/polyethylene glycol (PEG) precipitation, respectively. IPC viruses were added to samples subject to analysis prior to virus concentration to allow a global evaluation of the process: concentration, nucleic acid extraction, and amplification.

\section{Inoculation of IPC viruses}

Initial concentration of control viruses was set as $1 \times 10^{6} \mathrm{cg} /$ $\mathrm{mL}$ for liquid samples and $1 \times 10^{6} \mathrm{cg} / 25 \mathrm{~g}$ for food samples. In order to achieve this initial concentration, spiking volumes were calculated based on the known titers of IPC virus stocks $\left(9 \times 10^{10} \mathrm{PFU} / \mathrm{mL}\right.$ and $2.7 \times 10^{11} \mathrm{gc} / \mathrm{mL}$ of PP7 and $1.75 \times 10^{8} \mathrm{PFU} / \mathrm{mL}$ and $6 \times 10^{11} \mathrm{gc} / \mathrm{mL}$ of $\left.\mathrm{rAdV}-\mathrm{IPC}\right)$.

Each sample type (water, wastewater, or lettuce) was spiked with IPC virus stocks in the following way:

Tap water: For spiking a volume of 20 L of tap water sample, successive dilutions and homogenization were applied. Viral stocks were first diluted in $50 \mathrm{~mL}$, transferred to 2 and $10 \mathrm{~L}$ and finally $20 \mathrm{~L}$ of tap water.

Wastewater: Viral stocks were tenfold diluted in PBS and used to spike $50 \mathrm{~mL}$ of the sewage sample. Homogenization was performed using a vortex agitator.

Lettuce: Virus inoculum was prepared containing $1 \times 10^{6}$ genome copies in $10 \mu \mathrm{L}$ of both PP7 phage and rAdV-
IPC. Spiking was carried out by placing $10 \mu \mathrm{L}$ of the virus preparation as several small drops evenly onto the 25-g lettuce samples. After inoculation, the samples were kept for an hour in a biosafety cabinet until the spots had dried.

\section{Concentration methods}

The method applied for the recovery of viral particles from freshwater samples was described previously (Poma et al. 2013). Briefly, 20 L of dechlorinated tap water was spiked with PP7 and rAdV-IPC. Then, samples were pumped through the hollow-fiber ultrafiltration (HFUF) unit with a 50,000MW membrane cutoff (Microza AHP 1010, Pall Life Sciences, East Hills, NY, USA), until the volume was reduced to about $300 \mathrm{~mL}$. One elution step with $0.05 \mathrm{M}$ glycine/ $\mathrm{NaOH}$ pH 7 and $0.1 \%$ Tween 80 was performed to increase viral recovery. The final concentrated sample, $\sim 500 \mathrm{~mL}$, consisted of the mixture of the eluate from the HFUF unit plus the final retentate.

Viruses present in wastewater samples were concentrated by ultracentrifugation as previously described (Puig et al. 1995). Briefly, wastewater samples (44 mL) were spiked with rAdV-IPC and PP7 and $2 \mathrm{~mL}$ was taken as the initial sample. Samples $(42 \mathrm{~mL})$ were then ultracentrifuged $(110,000 \times \mathrm{g}$ for $1 \mathrm{~h}$ at $4{ }^{\circ} \mathrm{C}$ ). The sediment was suspended in $4 \mathrm{~mL} 0.25 \mathrm{~N}$ glycine buffer ( $\mathrm{pH}$ 9.5) and kept on ice for $30 \mathrm{~min}$. After incubation, samples were neutralized and $4 \mathrm{~mL}$ of PBS was added. Suspensions were centrifuged at $3000 \times g$ for $20 \mathrm{~min}$, supernatants were pelleted by ultracentrifugation $(110,000 \times g$ for $1 \mathrm{~h}$ at $4{ }^{\circ} \mathrm{C}$ ), and pellets were resuspended in $2 \mathrm{~mL}$ of PBS and stored at $-80{ }^{\circ} \mathrm{C}$.

Viruses from fresh lettuce were concentrated using alkaline elution followed by PEG precipitation as described before (ISO 15216 part 1). Briefly, lettuces were chopped and weighed in four replicates of $25 \mathrm{~g}$. Samples were spiked with rAdV-IPC and PP7 and the inoculum was used to determine the initial virus load. After spiking, samples were kept for $1 \mathrm{~h}$ at room temperature until spiked spots had dried. Each inoculated sample was placed in a sterile bag with $40 \mathrm{~mL}$ of Trisglycine-beef extract (TGBE) buffer containing 1140 units of pectinase from Aspergillus aculeatus and kept with constant shaking for $20 \mathrm{~min}$ at room temperature. The eluate was centrifuged at $10,000 \times g$ for $30 \mathrm{~min}$ at $4{ }^{\circ} \mathrm{C}$, the $\mathrm{pH}$ was
Table 1 Primers and probes used in qPCR to quantify rAdV-IPC

\begin{tabular}{lllll}
\hline Virus & Primer & Sense & Sequence $\left(5^{\prime}-3^{\prime}\right)$ & Reference \\
\hline AdV & JTVXF & $(+)$ & GGACGCCTCGGAGTACCTGAG & Jothikumar et al. (2005a) \\
& JTVXR & $(-)$ & ACIGTGGGGTTTCTGAACTTGTT & \\
& Probe PSC & $(+)$ & VIC-ACTGCCGTCGCGTAGTGTCGCC-BHQ & This work \\
\hline
\end{tabular}


neutralized, and $\mathrm{PEG} / \mathrm{NaCl}$ was added as a final concentration of $10 \%$ PEG $0.3 \mathrm{M} \mathrm{NaCl}$. After $1 \mathrm{~h}$ of rocking incubation, samples were centrifuged at $10,000 \times \mathrm{g}$ for $30 \mathrm{~min}$ at $5{ }^{\circ} \mathrm{C}$ and the pellet was resuspended in $1000 \mu \mathrm{L}$ of PBS. Finally, a chloroform/butanol (1:1) extraction was performed and the aqueous phase stored at $-80{ }^{\circ} \mathrm{C}$.

\section{Viral recovery of concentration methods}

Four replicate processes were performed for each virus concentration procedure (hollow-fiber ultrafiltration, ultracentrifugation, and alkaline elution followed by PEG precipitation). During HFUF and ultracentrifugation, two samples were taken: initial sample $(\mathrm{Si})$ and viral concentrate $(C)$. During alkaline elution followed by PEG precipitation of the virus present in lettuce, two samples were taken: stock solution used to spike lettuces (St) and viral concentrate $(C)$.

The percentage of viral recovery (\%VR) for PP7 and rAdVIPC was calculated as the ratio of the total number of $\mathrm{gc}$ in the concentrate and that in the initial sample $(\mathrm{Si})$ :

$\% \mathrm{VR}=\left(\frac{\text { genomic copies in } C}{\text { genomic copies in Si or St }}\right) \times 100$

An analogous formula was applied to calculate \%IVR based on the PFUs for PP7 and rAdV-IPC.

$\% \mathrm{IVR}=\left(\frac{\mathrm{PFU} \text { in } C}{\mathrm{PFU} \text { in } \mathrm{Si} \text { or } \mathrm{St}}\right) \times 100$

\section{Viral recovery of enteric viruses from sewage by ultracentrifugation}

Evaluation of virus concentration by ultracentrifugation was performed using four aliquots of $44 \mathrm{~mL}$ from $1 \mathrm{~L}$ of raw wastewater from a bovine slaughterhouse wastewater treatment plant. Viral recovery was calculated for the spiked IPC viruses as described above. To evaluate the outcome of enteric viruses naturally present in this kind of samples, concentrated by ultracentrifugation, we analyzed human enteric viruses in domiciliary sewage. Two domiciliary wastewater treatment plants were sampled and five raw sewage samples were concentrated and evaluated for the detection and quantification of human norovirus and enteroviruses in addition to the IPC viruses.

\section{Statistical analysis}

Recovery for each virus was expressed as the median and its range. A Mann-Whitney test (nonparametric) was used to analyze the difference in recovery between each virus and to compare recovery of total and infectious virus. Statistical significance was set at a level of $p<0.05$. Pearson's test was also run for correlation between viral recoveries for each control virus. Statistical analyses and graphics were performed with GraphPad Prism 5 (GraphPad Software Inc., CA, USA). Figures 1 and 3 were performed using Inkscape software.

\section{Accession numbers}

The IPC construction sequence is available under GenBank accession number KY359071.

\section{Results}

\section{Production of rAdV-IPC}

Recombinant adenovirus with the IPC construction (rAdV-IPC) (Fig. 1) was obtained by co-transfection of the packaging cell line 293A with two adenovirus-based vectors. At 8 days posttransfection, CPE was evident in transfected cells. These viral lysates were used to infect 293A cells in two successive passages until CPE was complete after $48 \mathrm{~h}$ of incubation. The production of rAdV-IPC was confirmed by CPE and PCR directed to IPC and its internal qPCR amplicons. Virus DNA was extracted from virus stocks and the IPC sequence was confirmed by sequencing. No mutations were introduced in the construction. The rAdV-IPC stock was quantified using the PFU assay for infectious particles and qPCR for genomic copies representing total virus particles. Virus titers were $1.75 \times 10^{8} \mathrm{PFU} / \mathrm{mL}$ and $6 \times 10^{11} \mathrm{gc} / \mathrm{mL}$, respectively. The presence of replication-competent adenoviruses in rAdV-IPC stocks was evaluated, and after four blind passages of rAdVIPC in A549 cells, no evident CPE was observed.

\section{Quantification of rAdV-IPC by qPCR}

rAdV-IPC was detected and quantified using a TaqMan assay directed to AdV PSC DNA. Linearity was observed between $1 \times 10^{2}$ and $7 \times 10^{7} \mathrm{gc} / \mu \mathrm{L}$. Viral stocks of huAdV3 and sewage samples with huAdV DNA were assayed with this qPCR and did not exhibit nonspecific probe hybridization.

\section{pH stability of rAdV-IPC and PP7}

Stability of rAdV-IPC and PP7 was evaluated at different $\mathrm{pH}$ values $(3,7$, and 10$)$ for a period of $18 \mathrm{~h}$. PP7 showed $3.25 \mathrm{log}$ reduction after $4 \mathrm{~h}$ at $\mathrm{pH} 3$, and no infectious bacteriophage was recovered after $18 \mathrm{~h}$ in this condition. No significant reduction was observed for PP7 during the period analyzed at $\mathrm{pH} 7$, but at $\mathrm{pH} 10$, a $2.14 \log$ reduction was observed after 18 h (Fig. 2 and Table S2 in the Supplementary material). Infectious rAdV-IPC concentration showed no significant 


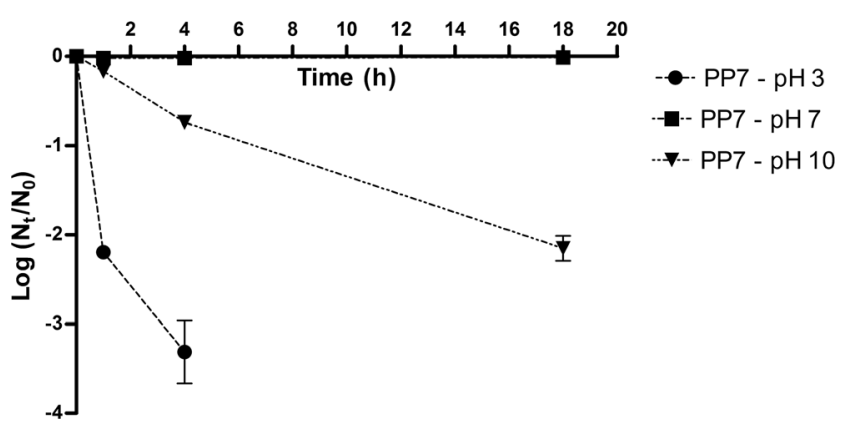

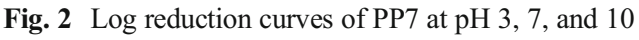

reduction at $\mathrm{pH} 3,7$, and 10 after $18 \mathrm{~h}$ at each condition (Table S3 in the Supplementary material).

\section{Evaluation of rAdV-IPC and PP7 as internal control viruses during virus concentration}

As mentioned in the "Materials and methods" section, rAdV-IPC and bacteriophage PP7 were spiked in tap water samples $(20 \mathrm{~L})$, sewage effluents $(44 \mathrm{~mL})$, and lettuce $(25 \mathrm{~g})$ and concentrated by ultrafiltration, ultracentrifugation, and elution/PEG precipitation, respectively (Fig. 3). Viruses were quantified as total viral particles using qPCR $(\mathrm{gc} / \mathrm{mL})$ or as infectious viral particles using PFU assays in samples taken along the process. \%VR and \%IVR were calculated for four independent experiments (raw data of viral concentrations and recoveries are presented in Tables S4, S5, S6, S7, S8, S9, and S10 in the Supplementary material).

HFUF yielded a wide range of total viral recoveries for rAdV and PP7 (Table 2). For this technique as well as for

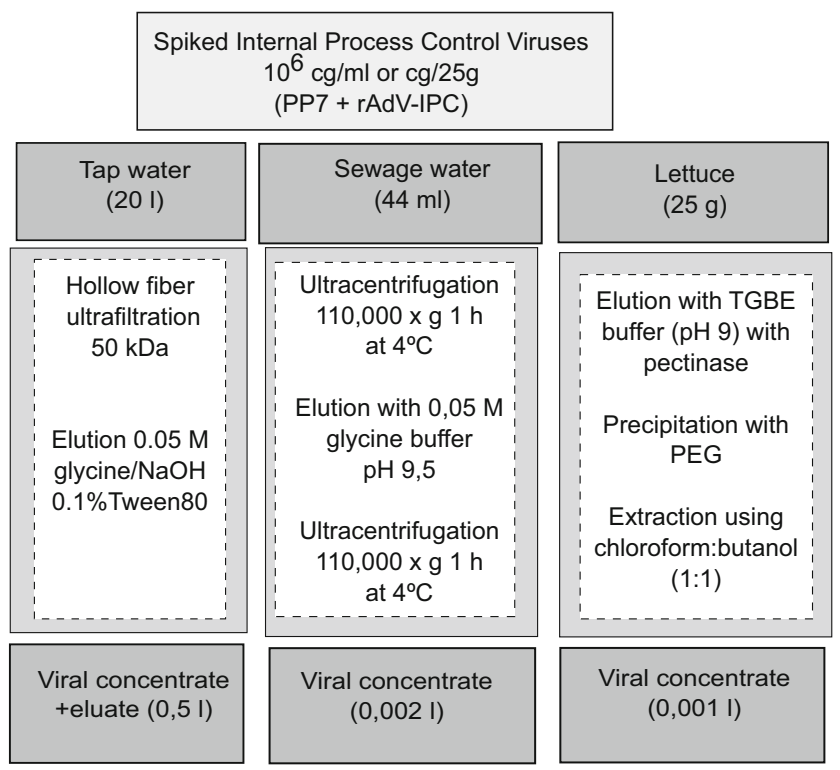

Fig. 3 Summary of procedures used to concentrate viruses from tap water, wastewater, and lettuce samples ultracentrifugation, the recoveries of both control viruses were not significantly different; however, IPC viruses did not correlate among all the individual samples. On the other hand, the total viral recovery of PP7 was significantly higher than that of adenovirus after elution and concentration of viruses from lettuce (Table 2).

Regarding the recovery of infectious virus by HFUF, there were no significant differences between both viruses or between total and infectious virus recoveries for each virus (Table 3). This indicates that infectivity was not affected significantly by the HFUF procedure. It is worth noticing that the $\%$ VR and \%IVR for PP7 decreased significantly when a basic instead of neutral elution was applied to the hollow-fiber cartridge (data not shown).

For ultracentrifugation, the \%IVR for rAdV-IPC was consistently higher than $100 \%$, showing a median of 269.5 (72.09-333.3\%) (Table 3). This phenomenon was also observed in four subsequent analyzed sewage samples (data not shown). The initial concentration of rAdV-IPC spiked in wastewater samples $(546 \pm 426.8 \mathrm{PFU} / \mathrm{mL})$ was significantly lower $(p<0.004)$ than the concentration expected for the titer of the viral stock and dilution factor $\left(1.46 \times 10^{5} \mathrm{PFU} / \mathrm{mL}\right.$ ). When a clean water matrix (as the tap water for the HFUF concentration) was used, this behavior was not observed. This experimental setback could indicate that rAdV-IPC could be absorbed to sediments or other particulate materials in the sewage sample. However, this proposed interaction between the virus and solid material was not disrupted by treatment with $10 \%$ beef extract and 0.05 M EDTA previous to PFU quantification; no significant differences were observed in the initial PFUs or \%IVR with or without this treatment (data not shown). Although it was not possible to obtain a reliable measure of rAdV-IPC infectious virus recovery by ultracentrifugation, it can be concluded that the methodology does allow recovering infectious virus.

On the other hand, the procedure for elution and concentration of control viruses from lettuce affected viral infectivity drastically, with recovery of $0.00 \% \mathrm{rAdV}-\mathrm{IPC}$ and only $0.06 \%$ $(0.01-0.08 \%)$ of infectious PP7 (Table 3).

\section{Comparison of \% VR of control viruses and enteric viruses in sewage samples}

Five independent samples from two wastewater treatment plants were spiked with both IPC viruses and concentrated by ultracentrifugation. Human enteroviruses and norovirus were detected and quantified in samples pre- and postconcentration. When enteric viruses were quantified in both extracts, the \%VR was calculated. Recoveries are shown in Table 4 and viral loads in Tables S11 and S12 in the Supplementary material. No significant differences were 
Table 2 Viral recovery (\%VR) of total PP7 and rAdV-gB in ultrafiltration, ultracentrifugation, and alkaline elution-PEG precipitation procedures

\begin{tabular}{|c|c|c|c|c|c|c|}
\hline Sample & \multicolumn{2}{|l|}{ Tap water } & \multicolumn{2}{|c|}{ Sewage water } & \multicolumn{2}{|l|}{ Lettuce } \\
\hline $\begin{array}{l}\text { Concentration } \\
\text { method }\end{array}$ & \multicolumn{2}{|c|}{ Hollow fiber ultrafiltration } & \multicolumn{2}{|c|}{ Ultracentrifugation } & \multicolumn{2}{|c|}{ Basic elution-PEG precipitation } \\
\hline Virus & rAdV-IPC & PP7 & rAdV-IPC & PP7 & rAdV-IPC & PP7 \\
\hline Median & 71.88 & 29.67 & 12.08 & 12.27 & 2.76 & 17.36 \\
\hline Range & $2.10-84.42$ & $13.54-84.62$ & $5.05-13.71$ & $6.98-13.27$ & $0.00-3.44$ & $14.74-18.82$ \\
\hline$p$ & 0.8857 & & 1.0000 & & $<0.029$ & \\
\hline
\end{tabular}

observed in the recovery between control viruses and enteric viruses present in sewage (in all cases, $p>0.05$ ).

\section{Discussion}

In this study, we produced a recombinant adenovirus for application as IPC and compared it with another IPC virus, bacteriophage PP7. rAdV-IPC is based on a recombinant AdV5 vector and includes a genetic tag composed of seven PSCs from different human viruses present either in aquatic environments or in food samples. rAdV-IPC possesses the quality of being a nonreplicating virus. However, its viability can be tested using 293A cells, although plaques formed by the IPC viruses cannot be distinguished from wild-type adenoviruses. In addition, the DNA IPC construction could be used as an exogenous positive control to assess whether the samples contain any components that inhibit PCR amplification of the seven enteric viruses represented in the construction, as previously published (Hata et al. 2014). These two IPC viruses could represent two different types of enteric viruses present in environmental samples, both naked viral particles, with DNA doublestranded or RNA single-stranded genomes.

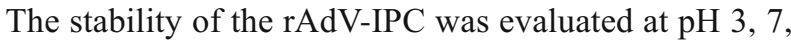
and 10 , given that these incubation conditions are usually used in alkaline elution or acidic rinse during virus concentration methods from environmental samples. No loss of infectious adenovirus was noticed at the three $\mathrm{pH}$ values evaluated. These results agree with previously published analysis of AdV stability (Rexroad et al. 2006) and are consistent with the pattern of enteric spread of the virus. On the other hand, bacteriophage PP7 exhibited a different behavior, showing high loss of infectivity at $\mathrm{pH} 3$ and 10, with no significant decay at $\mathrm{pH} 7$ for $18 \mathrm{~h}$. In a previous study of our work group, the recovery of PP7 decreased significantly when a basic elution was applied to the hollow-fiber cartridge. The instability at acidic and basic conditions of bacteriophages has been thoroughly described (Jończyk et al. 2011). For MS2 and Q $\beta$, members of the family Leviviridae like PP7, the inactivation rates of both coliphages increase when the $\mathrm{pH}$ is below 6 or above 8 (Feng et al. 2003). This should be taken into consideration when using bacteriophages as IPC viruses in procedures that involve drastic $\mathrm{pH}$ changes.

The quantification of viral recovery in processes involving environmental and food samples is a challenging task and usually has broad range and variability not only between studies for different viruses but also within studies for the same virus. For quantitative microbiological risk assessment, the recovery value is needed to correct the virus concentration in the source matrix, using however a beta distribution of this parameter instead of a single value (Petterson et al. 2015).

In this work, HFUF and ultracentrifugation, which depend on the size exclusion and sedimentation coefficient of the viral particle, respectively, showed no significant differences in viral recovery for the two applied dissimilar IPC viruses. However, it has been reported that, according to an uncertainty analysis, the recovery by HFUF is strongly influenced by

Table 3 Infectious viral recovery (\%IVR) of PP7 and rAdV-gB in ultrafiltration, ultracentrifugation, and alkaline elution-PEG precipitation procedures

\begin{tabular}{|c|c|c|c|c|c|c|}
\hline Sample & \multicolumn{2}{|l|}{ Tap water } & \multicolumn{2}{|c|}{ Sewage water } & \multicolumn{2}{|l|}{ Lettuce } \\
\hline $\begin{array}{l}\text { Concentration } \\
\text { method }\end{array}$ & \multicolumn{2}{|c|}{ Hollow fiber ultrafiltration } & \multicolumn{2}{|c|}{ Ultracentrifugation } & \multicolumn{2}{|c|}{ Basic elution-PEG precipitation } \\
\hline Virus & rAdV-IPC & PP7 & rAdV-IPC & PP7 & rAdV-IPC & PP7 \\
\hline Median & 75.52 & 56.82 & 269.5 & 7.675 & 0.00 & 0.06 \\
\hline Range & $51.33-125.20$ & $55.00-110.12$ & $72.09-333.3$ & $3.42-15.55$ & 0.00 & $0.01-0.08$ \\
\hline$p$ & 0.8571 & & 0.0286 & & nd & \\
\hline
\end{tabular}

nd not determined 
Table 4 Viral recovery (\%VR) of spiked viruses (PP7 and rAdVIPC), norovirus, and enterovirus from raw sewage samples concentrated by ultracentrifugation

\begin{tabular}{llllll}
\hline Wastewater treatment plant & Sampling date & PP7 & rAdV-IPC & NoV GII & EV \\
\hline WWTP1 & June 2016 & 1.25 & 1.37 & nd & nd \\
& August 2016 & 6.02 & 1.98 & 6.06 & nd \\
& November 2016 & 2.97 & 5.48 & nd & nd \\
WWTP2 & December 2016 & 2.10 & 14.22 & 2.78 & 3.29 \\
& December 2016 & 2.72 & 13.93 & 12.88 & 2.39 \\
& Median & 2.72 & 5.48 & 6.06 & 2.84 \\
& Range & $1.25-6.02$ & $1.37-14.22$ & $2.78-6.06$ & $2.39-3.29$ \\
\hline
\end{tabular}

$n d$ not determined

different conditions such as the type of microorganism and its interactions in different water matrixes and with different filters (Wu et al. 2013).

The recovery of enteric viruses naturally present in sewage samples was also analyzed. Human noroviruses and enteroviruses showed no significant differences with control viruses in their recovery using ultracentrifugation as concentration method in five different samples. No clear correlation was observed among enteric viruses with neither of the IPC viruses. When the $\%$ VR was below $5 \%$, concentration was not effective since viral titer in the concentrated samples was below the initial titers.

Another characteristic of the ultracentrifugation process was the consistent result of recovery values of infectious rAdV-IPC over $100 \%$. Recovery values higher than $100 \%$ are experimental setbacks found frequently in calculating viral recovery in this and other works (Hill et al. 2007; Liu et al. 2012; Petterson et al. 2015; Rhodes et al. 2016). One possible explanation to this phenomenon is the aggregation of viral particles in the initial sample, which tend to disintegrate during the procedure. Some authors argue that this effect biases the results toward higher recovery values. In this study, this might represent a differential behavior in the adsorption or aggregation of rAdV-IPC and PP7 to the solid or organic materials present in sewage samples. The presence of wild-type adenovirus in sewage samples could contribute to the increase in the number of infective particles detected after the concentration, but their relative amount to the inoculated rAdV-IPC would be negligible, since no infectious wild-type adenovirus was recovered in A549 cells from these samples (data not shown).

Leafy green vegetables are one of the principal commodities involved in foodborne outbreaks associated with norovirus, Escherichia coli O157:H7, and Salmonella spp. (FAO/WHO 2008). Adsorption of enteric viruses to vegetable surfaces makes necessary to elute them from the leaves prior to concentration. In this work, bacteriophage PP7 was significantly more recovered than AdV (14.7418.82 vs $0.00-3.44 \%$ ). Viral recovery of PP7 from lettuce was slightly higher than that previously published $(0.01-$ $10.82 \%$ ) (Brandão et al. 2014). The infectivity of both IPC viruses was significantly affected by the concentration procedure. Evaluating the infectivity of pathogenic viruses in food and water samples is highly challenging, due not only to the low levels of infectious viral particles in the environment but also to the effects of the procedures used for the concentration of viral particles.

The use of an internal control virus should be mandatory whenever an environmental or food virus analysis is to be carried out, since it is common to observe high variability between assays. Which control virus must be applied for each specific process should be evaluated by comparing its performance with that of the target virus of the analysis. One alternative approach could be the simultaneous use of virus controls with dissimilar characteristics and behaviors, especially when different enteric viruses are to be detected after the concentration procedure.

Acknowledgments This work was supported by grants from Universidad de Buenos Aires (SECyT-UBA 20020100100405) and Agencia Nacional de Promoción Científica y Tecnológica (ANPCyT; PICT 2012-2679), Argentina. Funding sources had no involvement in the study design, collection, analysis and interpretation of data, writing of the paper, or the decision to submit the article for publication. We thank Drs. Juan Stupka, Karina Gomes, Daniel Cisterna, and Leila Martínez from the Virology Department of the Instituto Nacional de Enfermedades Infecciosas - ANLIS Dr. Carlos G. Malbrán for their help with norovirus and enterovirus quantitation. We thank María Victoria Gonzalez Eusevi for correction of the English language.

Compliance with ethical standards This article does not contain any studies with human participants or animals performed by any of the authors.

Conflict of interest The authors declare that they have no conflict of interest.

\section{References}

Bae J, Schwab KJ (2008) Evaluation of murine norovirus, feline calicivirus, poliovirus, and MS2 as surrogates for human norovirus in a model of viral persistence in surface water and groundwater. Appl Environ Microbiol 74:477-484. doi:10.1128/AEM.02095-06

Barardi RM, Garcia LAT, Nascimento MA, Barardi CRM (2014) Effect of UV light on the inactivation of recombinant human adenovirus and murine norovirus seeded in seawater in shellfish depuration tanks. Food Env Virol. doi:10.1007/s12560-014-9177-x 
Beer KD, Gargano JW, Roberts VA, Hill VR, Garrison LE, Kutty PK, Hilborn ED, Wade TJ, Fullerton KE, Yoder JS (2015) Outbreaks associated with environmental and undetermined water exposuresUnited States, 2011-2012. Morb Mortal Wkly Rep 64:842-848. doi:10.1136/injuryprev-2011-040066

Bosch A, Guix S, Sano D, Pintó RM (2008) New tools for the study and direct surveillance of viral pathogens in water. Curr Opin Biotechnol 19:295-301. doi:10.1016/j.copbio.2008.04.006

Brandão MLL, Almeida DO, Bispo FCP, Bricio SML, Marin VA, Miagostovich MP (2014) Assessment of microbiological contamination of fresh, minimally processed, and ready-to-eat lettuces (Lactuca sativa), Rio de Janeiro State, Brazil. J Food Sci 79: M961-M966. doi:10.1111/1750-3841.12459

Charles KJ, Shore J, Sellwood J, Laverick M, Hart a, Pedley S (2009) Assessment of the stability of human viruses and coliphage in groundwater by PCR and infectivity methods. J Appl Microbiol 106:1827-1837. doi:10.1111/j.1365-2672.2009.04150.x

Clokie M, Kropinski AM (2001) Bacteriophages: methods and protocols.

Costafreda MI, Bosch A, Pintó RM (2006) Development, evaluation, and standardization of a real-time TaqMan reverse transcription-PCR assay for quantification of hepatitis A virus in clinical and shellfish samples. Appl Environ Microbiol 72:3846-3855. doi:10.1128/ AEM.02660-05

Coudray C, Merle G, Martin-latil S, Guillier L, Perelle S (2013) Comparison of two extraction methods for the detection of hepatitis A virus in lettuces using the murine norovirus as a process control. $\mathrm{J}$ Virol Methods 193:96-102. doi:10.1016/j.jviromet.2013.05.003

Cromeans TL, Lu X, Erdman DD, Humphrey CD, Hill VR (2008) Development of plaque assays for adenoviruses 40 and 41. J Virol Methods 151:140-145. doi:10.1016/j.jviromet.2008.03.007

Eurosurveillance Editorial Team (2014) Hepatitis A outbreak: report on results from food trace-back investigation. Euro Surveill 36:20896

FAO/WHO (2008) Microbiological hazards in fresh fruits and vegetables: meeting report.

Feng YY, Ong SL, Hu JY, Tan XL, Ng WJ (2003) Effects of pH and temperature on the survival of coliphages MS2 and Qbeta. J Ind Microbiol Biotechnol 30:549-552. doi:10.1007/s10295-003-0080-y

Hata A, Katayama H, Kitajima M, Visvanathan C, Nol C, Furumai H (2011) Validation of internal controls for extraction and amplification of nucleic acids from enteric viruses in water samples. Appl Environ Microbiol 77:4336-4343. doi:10.1128/AEM.00077-11

Hata A, Katayama H, Kojima K, Sano S, Kasuga I, Kitajima M, Furumai $H$ (2014) Effects of rainfall events on the occurrence and detection efficiency of viruses in river water impacted by combined sewer overflows. Sci Total Environ 468-469:757-763. doi:10.1016/j. scitotenv.2013.08.093

He TC, Zhou S, Costa LD, da Costa LT, Yu J, Kinzler KW, Vogelstein B (1998) A simplified system for generating recombinant adenoviruses. Proc Natl Acad Sci 95:2509-2514. doi:10.1073/pnas.95.5. 2509

Hill VR, Kahler AM, Jothikumar N, Johnson TB, Hahn D, Cromeans TL (2007) Multistate evaluation of an ultrafiltration-based procedure for simultaneous recovery of enteric microbes in 100-liter tap water samples. Appl Environ Microbiol 73:4218-4225. doi:10.1128/ AEM.02713-06

Jończyk E, Kłak M, Międzybrodzki R, Górski A (2011) The influence of external factors on bacteriophages - review. Folia Microbiol (Praha) 56:191-200. doi:10.1007/s12223-011-0039-8

Jothikumar N, Cromeans TL, Hill VR, Lu X, Sobsey MD, Erdman DD (2005a) Quantitative real-time PCR assays for detection of human adenoviruses and identification of serotypes 40 and 41. Appl Environ Microbiol 71:3131-3136. doi:10.1128/AEM.71.6.3131

Jothikumar N, Cromeans TL, Sobsey MD, Robertson BH (2005b) Development and evaluation of a broadly reactive TaqMan assay for rapid detection of hepatitis A virus. Appl Environ Microbiol 71:3359-3363. doi:10.1128/AEM.71.6.3359
Jothikumar N, Lowther JA, Henshilwood K, Lees DN, Hill VR, Vinje J (2005c) Rapid and sensitive detection of noroviruses by using TaqMan-based one-step reverse transcription-PCR assays and application to naturally contaminated shellfish samples. Appl Environ Microbiol 71:1870-1875. doi:10.1128/AEM.71.4.1870

Jothikumar N, Cromeans TL, Robertson BH, Meng XJ, Hill VR (2006) A broadly reactive one-step real-time RT-PCR assay for rapid and sensitive detection of hepatitis E virus. J Virol Methods 131:6571. doi:10.1016/j.jviromet.2005.07.004

Julian TR, Schwab KJ (2012) Challenges in environmental detection of human viral pathogens. Curr Opin Virol 2:78-83. doi:10.1016/j. coviro.2011.10.027

Kilpatrick DR, Yang CF, Ching K, Vincent A, Iber J, Campagnoli R, Mandelbaum M, De L, Yang SJ, Nix A, Kew OM (2009) Rapid group-, serotype-, and vaccine strain-specific identification of poliovirus isolates by real-time reverse transcription-PCR using degenerate primers and probes containing deoxyinosine residues. J Clin Microbiol 47:1939-1941. doi:10.1128/JCM.00702-09

Lees D (2010) International standardisation of a method for detection of human pathogenic viruses in molluscan shellfish. Food Environ Virol 2:146-155. doi:10.1007/s12560-010-9042-5

Liu P, Hill VR, Hahn D, Johnson TB, Pan Y, Jothikumar N, Moe CL (2012) Hollow-fiber ultrafiltration for simultaneous recovery of viruses, bacteria and parasites from reclaimed water. J Microbiol Methods 88:155-161. doi:10.1016/j.mimet.2011.11.007

Loisy F, Atmar RL, Guillon P, Le Cann P, Pommepuy M, Le Guyader FS (2005) Real-time RT-PCR for norovirus screening in shellfish. J Virol Methods 123:1-7. doi:10.1016/j.jviromet.2004.08.023

Martin-Latil S, Hennechart-Collette C, Guillier L, Perelle S (2014) Method for HEV detection in raw pig liver products and its implementation for naturally contaminated food. Int J Food Microbiol 176:1-8. doi:10.1016/j.jjfoodmicro.2014.01.016

Matsushita T, Shirasaki N, Tatsuki Y, Matsui Y (2013) Investigating norovirus removal by microfiltration, ultrafiltration, and precoagulation-microfiltration processes using recombinant norovirus virus-like particles and real-time immuno-PCR. Water Res 47:5819-5827. doi:10.1016/j.watres.2013.07.004

Monpoeho S, Maul A, Schwartzbrod L, Billaudel S, Virologie LD, Dieu CHUH, Processing D (2001) Best viral elution method available for quantification of enteroviruses in sludge by both cell culture and reverse transcription-PCR. Appl Environ Microbiol 67:24842488. doi:10.1128/AEM.67.6.2484

Pal A, Sirota L, Maudru T, Peden K, Lewis AM (2006) Real-time, quantitative PCR assays for the detection of virus-specific DNA in samples with mixed populations of polyomaviruses. J Virol Methods 135:32-42. doi:10.1016/j.jviromet.2006.01.018

Petterson S, Grøndahl-Rosado R, Nilsen V, Myrmel M, Robertson LJ (2015) Variability in the recovery of a virus concentration procedure in water: implications for QMRA. Water Res 87:79-86. doi:10. 1016/j.watres.2015.09.006

Poma HR, Rajal VB, Blanco Fernández MD, Barril PA, Giordano MO, Masachessi G, Martínez LC, Isa MB, Freire MC, López Riviello G, Cisterna D, Nates SV, Mbayed VA (2013) Evaluation of concentration efficiency of the Pseudomonas aeruginosa phage PP7 in various water matrixes by different methods. Environ Monit Assess 185: 2565-2576. doi: 10.1007/s10661-012-2731-9

Puig M, Allard A, Lucena F, Wadell G, Jofre J, Girones R (1995) Detection of adenovirus and enterovirus by PCR amplification in polluted waters. Water Sci Technol 31:351-357. doi:10.1016/02731223(95)00291-T

Rajal VB, McSwain BS, Thompson DE, Leutenegger CM, Kildare BJ, Wuertz S (2007) Validation of hollow fiber ultrafiltration and realtime PCR using bacteriophage PP7 as surrogate for the quantification of viruses from water samples. Water Res 41:1411-1422. doi: 10.1016/j.watres.2006.12.034 
Rexroad J, Evans RK, Middaugh CR (2006) Effect of pH and ionic strength on the physical stability of adenovirus type 5. J Pharm Sci 95:237-247. doi:10.1002/jps.20496

Rhodes ER, Huff EM, Hamilton DW, Jones JL (2016) The evaluation of hollow-fiber ultrafiltration and celite concentration of enteroviruses, adenoviruses and bacteriophage from different water matrices. J Virol Methods 228:31-38. doi:10.1016/ j.jviromet.2015.11.003

Summa M, von Bonsdorff C-H, Maunula L (2012) Evaluation of four virus recovery methods for detecting noroviruses on fresh lettuce, sliced ham, and frozen raspberries. J Virol Methods 183:154-160. doi:10.1016/j.jviromet.2012.04.006

Verhoef L, Hewitt J, Barclay L, Ahmed SM, Lake R, Hall AJ, Lopman B, Kroneman A, Vennema H, Vinjé J, Koopmans M (2015) Norovirus genotype profiles associated with foodborne transmission, 1999 2012. Emerg Infect Dis 21:592-599. doi:10.3201/eid2104.141073

Victoria M, Guimarães F, Fumian T, Ferreira F, Vieira C, Leite JP, Miagostovich M (2009) Evaluation of an adsorption-elution method for detection of astrovirus and norovirus in environmental waters. J Virol Methods 156:73-76. doi:10.1016/j.jviromet.2008.11.003

Wu J, Simmons OD, Sobsey MD (2013) Uncertainty analysis of the recovery of hollow-fiber ultrafiltration for multiple microbe classes from water: a Bayesian approach. J Microbiol Methods 93:161-167. doi:10.1016/j.mimet.2013.03.005

Zeng SQ, Halkosalo A, Salminen M, Szakal ED, Puustinen L, Vesikari T (2008) One-step quantitative RT-PCR for the detection of rotavirus in acute gastroenteritis. J Virol Methods 153:238-240. doi:10.1016/ j.jviromet.2008.08.004 